\title{
KAJIAN KEBUTUHAN ANGKUTAN LAYANAN PERGERAKAN INTERNAL KAMPUS INSTITUT TEKNOLOGI SUMATERA
}

\author{
Siti RAHMA ${ }^{1 *}$, Goldie Melinda WIJAYANTI ${ }^{2}$, Zenia F SARASWATI ${ }^{2}$ \\ ${ }^{1}$ Program Studi Teknik Sipil, Jurusan Teknologi Infrastruktur dan Kewilayahan, Institut Teknologi \\ Sumatera, Lampung Selatan, Indonesia \\ ${ }^{2}$ Program Studi Perencanaan Wilayah dan Kota, Jurusan Teknologi Infrastruktur dan Kewilayahan, \\ Institut Teknologi Sumatera, Lampung Selatan, Indonesia \\ *Email korespondensi: siti.rahma@si.itera.ac.id
}

[diterima: 31 Maret 2021, disetujui: 1 Juni 2021]

\begin{abstract}
Besides of buildings, accessibility in moving between buildings is one of important factor in learning activities. Accessibility in transportation will be achieved if the ease of moving in terms of time, cost and distance can be accommodated efficiently. Based on the Masterplan for the Acceleration of Campus Development at the Sumatera Institute of Technology 2017-2027, in the next 10 years, there would be additional buildings in ITERA, where lead to increasing of internal movements. One of the accessibility's problems is, with 275 hectares of total land area, there is no public transportation serving. The internal movement of the academic community is carried out using private vehicles, online transportation, or by walk. There are several analyzes will be carried out to find out how important the internal movement facilities in the ITERA campus area, and the types of vehicles that can serve the movement. The result revealed that the peak hour of transfer of internal campus movements were carried out by all ITERA academicians at 15.00-16.00 WIB. Based on analysis of the existing geometric conditions, it can be seen that the lane width on the ITERA internal ring road is more than $2.5 \mathrm{~m}$, which means that it is sufficient to serve the movement Light Vehicles (LV) and medium or large buses according to the type classification. In addition, from the choice group, more than $50 \%$ of respondents stated that they are willing to use public transportation for the internal movements at the ITERA campus if these facilities are already available.
\end{abstract}

Key words: transportation, internal, campus, ITERA.

\section{INTISARI}

Selain fasilitas berupa gedung fisik, aksesibilitas dalam perpindahan antar gedung merupakan faktor pendukung dalam kegiatan belajar mengajar. Aksesibilitas dalam transportasi akan tercapai apabila kemudahan untuk berpindah dari sisi waktu, biaya, dan jarak dapat diakomodasi dengan efektif dan efisien. Berdasarkan Masterplan Percepatan Pembangunan Kampus Institut Teknologi Sumatera 20172027, dapat disimpulkan bahwa dalam jangka waktu 10 tahun kedepan, masih akan terdapat penambahan bangunan fisik di ITERA, sehingga pergerakan atau perpindahan yang terjadi di dalam wilayah kampus akan meningkat. Salah satu permasalahan aksesibilitas pergerakan kampus adalah, dengan total luas lahan sebesar $275 \mathrm{Ha}$, belum tersedianya angkutan yang melayani wilayah dalam kampus. Pergerakan internal sivitas akademika dilakukan dengan menggunakan kendaraan pribadi, angkutan online, maupun berjalan. Dalam merencanakan angkutan layanan internal kampus, akan dilakukan beberapa analisis untuk mengetahui seberapa pentingnya sarana tersebut, dan jenis kendaraan yang dapat melayani permintaan pergerakan. Berdasarkan hasil survei, diketahui bahwa pergerakan internal kampus dilakukan oleh seluruh sivitas akademika ITERA, dengan waktu puncak yaitu pukul 15.00-16.00 WIB. Dari analisis kondisi geometri eksisting, diketahui bahwa lebar lajur pada ruas jalan lingkar internal ITERA melebihi 2,5 m yang artinya memadai untuk melayani pergerakan dengan jenis kendaraan mobil penumpang ringan atau Light Vehicle (LV) dan bus sedang atau besar sesuai dengan klasifikasi jenis kendaraan angkutan umum darat. Selain itu, dari golongan kelompok choice didapatkan lebih dari 50\% responden yang 
menyatakan untuk bersedia menggunakan angkutan umum yang melayani pergerakan internal kampus ITERA apabila fasilitas tersebut telah tersedia. Hal ini menandakan bahwa kampus ITERA telah membutuhkan perancangan kebutuhan angkutan umum untuk melayani pergerakan internal kampus.

Kata kunci: transportasi, internal, kampus, ITERA.

\section{PENDAHULUAN}

Kegiatan belajar dan mengajar di kampus merupakan salah satu bagian dari kegiatan pendidikan tinggi untuk menghasilkan lulusan universitas yang berkompeten. Selain fasilitas berupa gedung fisik, aksesibilitas dalam perpindahan antar gedung merupakan faktor pendukung dalam kegiatan belajar mengajar. Aksesibilitas dalam transportasi akan tercapai apabila kemudahan untuk berpindah dari sisi waktu, biaya, dan jarak dapat diakomodasi dengan efektif dan efisien.

Institut Teknologi Sumatera (ITERA) merupakan institusi negeri pertama di pulau Sumatera, yang berada di perbatasan kabupaten Lampung Selatan dan Kota Bandar Lampung. Secara administrasi kampus ITERA berada di kabupaten Lampung Selatan, yang hanya berjarak sejauh $\pm 1 \mathrm{~km}$ dari Gerbang Tol Kotabaru, yang merupakan salah satu akses dari dan menuju Jalan Tol Trans Sumatera. Pada tahun 2019, jumlah mahasiswa ITERA sebanyak 9.412 mahasiswa, 346 dosen, dan 241 tenaga kependidikan dan outsourcing. Menurut Masterplan Percepatan Pembangunan Kampus Institut Teknologi Sumatera 20172027, dalam jangka waktu 5 (lima) tahun kedepan atau hingga tahun 2023, akan terdapat 50 Program Studi taraf Strata-1 (S1), 12 Program Studi taraf Strata-2 (S2), dan 25 Program Diploma. Sebagai perguruan tinggi negeri baru, perkembangan fisik di ITERA dapat dikatakan cukup pesat, hal ini ditunjukkan oleh ketersediaan bangunan gedung di ITERA hingga tahun 2020 yaitu sejumlah 14 gedung, dengan 10 diantaranya digunakan sebagai kegiatan perkuliahan dan praktikum, serta 4 gedung asrama yang dihuni oleh mahasiswa dan sebagian staf pegawai ITERA.

Dengan demikian, dapat disimpulkan bahwa dalam jangka waktu 10 tahun kedepan, masih akan terdapat penambahan sumber daya baik berupa Sumber Daya Manusia maupun bangunan fisik di ITERA, sehingga pergerakan atau perpindahan yang terjadi di dalam wilayah kampus akan semakin meningkat. Salah satu permasalahan aksesibilitas pergerakan yang akan timbul adalah, dengan total luas lahan sebesar 275 $\mathrm{Ha}$, hingga saat ini belum tersedianya angkutan yang melayani wilayah dalam kampus. Pergerakan sivitas akademika di dalam kampus dilakukan dengan menggunakan kendaraan pribadi, angkutan online, maupun berjalan kaki. Adapun menurut Basuki (2020), efek lain dari adanya banyaknya pergerakan dan volume lalu lintas yang tinggi, serta didominasi oleh kendaraan bermotor, adalah permasalahan polusi dan kenyamanan. Perencanaan transportasi yang baik akan turut mendukung kegiatan akademik yang berlangsung di suatu institusi pendidikan, hal ini selaras dengan penelitian yang dilakukan oleh Diayudha (2011) mengenai efektifitas bus kampus dari persepsi mahasiswa, selain meningkatkan nilai jual dari kampus, angkutan ini juga bermanfaat dari sisi ekonomi sivitas akademika, yaitu berkurangnya biaya transportasi. Dampak positif lainnya yaitu selain untuk meminimalisasi penggunaan waktu untuk berpindah, penerapan ilmu dan teknologi transportasi yang berkelanjutan akan mempengaruhi sikap dan kedisiplinan sivitas akademika dalam menggunakan fasilitas umum.

Dari hasil penelitian oleh Rugayah (2013), lebih dari 50\% mahasiswa universitas negeri di Malaysia, menggunakan bus kampus sebagai moda untuk berpindah di dalam wilayah kampus, hal ini dikarenakan responden merasa lebih praktis untuk berpindah menggunakan angkutan umum dibandingkan kendaraan pribadi. Hal ini pun memiliki dampak positif, antara lain penggunaan bus kampus bersifat ramah lingkungan khususnya pengurangan limbah 
karbon, dikarenakan dapat mengurangi penggunaan mobil pribadi yang dapat menyebabkan kemacetan khususnya di gerbang masuk dan keluar kampus. Sistem transportasi yang berkelanjutan merupakan alternatif penghematan energi dengan memanfaatkan sistem transportasi masal (Sulviawan, 2014).

Dari penelitian oleh Balsas (2003), beberapa aspek yang harus diperhatikan untuk menyukseskan kebijakan pengunaan kendaraan tidak bermotor di wilayah kampus yaitu strategi TDM (Transportation Demand Management), aspek perencanaan, asosiasi pendukung, ketersediaan fasilitas, kegiatan sosialisasi, dan kebijakan yang 'memaksa' konsumen untuk mengurangi pemakaian kendaraan bermotor. Adapun kebijakan tersebut harus diiringi dengan penyediaan fasilitas angkutan umum dalam kampus yang dapat digunakan oleh sivitas akademika. Oleh karena itu melalui penelitian ini, akan dilakukan kajian kebutuhan bus kampus yang akan melayani wilayah kampus ITERA. Selain bertujuan untuk meningkatkan aksesibilitas, penelitian ini juga bertujuan untuk menciptakan kampus yang ramah lingkungan selaras dengan slogan dari kampus ITERA yaitu, Smart, Friendly, and Forrest Campus.

\section{Jalur dan Lajur Lalu Lintas}

Berdasarkan modul Dasar-Dasar Perencanaan Geometrik Jalan oleh Pusdiklat Jalan, Perumahan, Permukiman, dan Pengembangan Infrastruktur Wilayah (2017), Jalur lalu lintas adalah keseluruhan bagian perkerasan jalan yang diperuntukkan untuk lalu lintas kendaraan. Jalur lalu lintas terdiri dari beberapa lajur kendaraan. Lajur kendaraan yaitu bagian dari jalur lalu lintas yang khusus diperuntukkan untuk dilewati oleh satu rangkaian kendaraan beroda empat atau lebih dalam satu arah. Oleh sebab itu, jumlah lajur minimal untuk jalan 2 arah adalah 2 dan pada umumnya disebut sebagai jalan 2 lajur 2 arah. Jalur lalu lintas untuk 1 arah minimal terdiri dari 1 lajur lalu lintas. Berikut merupakan ketentuan jumlah lajur dan arah pada jalan perkotaan:

1. Jalan dua-lajur dua-arah (2/2 UD)
2. Jalan empat-lajur dua-arah

- Tak-terbagi (tanpa median) (4/2 UD)

- Terbagi (dengan median) (4/2 D)

3. Jalan enam-laju dua-arah terbagi (6/2 D)

4. Jalan satu-arah (1-3/1).

\section{Sistem Transportasi Perkotaan}

Menurut Khisty (2003), bentuk fisik dari kebanyakan sistem transportasi tersusun atas empat elemen dasar yaitu:

a. Sarana perhubungan (link): Jalan raya atau jalur yang menghubungkan dua titik atau lebih, pipa, jalur ban berjalan (belt coveyor), jalur laut, jalur penerbangan juga dapat dikategorikan sebagai sarana perhubungan.

b. Kendaraan: alat yang memindahkan manusia dan barang dari suatu titik ke titik lain di sepanjang sarana perhubungan seperti mobil, bus, dan sebagainya.

c. Terminal: Titik-titik dimana perjalanan orang dan barang dimulai atau berakhir, seperti terminal bus dan bandar udara.

d. Manajemen dan tenaga kerja: Orangorang yang membuat, mengoperasikan, mengatur dan memelihara sarana perhubungan, kendaraan dan terminal.

Agar tata kelola transportasi dapat berjalan optimal dibutuhkan suatu perencanaan transportasi yang matang. Perencanaan transportasi sangat perlu dilakukan agar menciptakan sistem yang efisien dan efektif. Perencanaan transportasi untuk mencapai sasaran yang diinginkan, menurut Adisasmita (2011), dengan menetapkan kebijakan tentang beberapa hal berikut:

1. Sistem kegiatan (tata guna lahan). Rencana tata guna lahan yang baik (lokasi tokoh, sekolah, pasar, kantor dan lainnya) dapat mengurangi kebutuhan akan perjalanan yang panjang menjadi lebih dekat dan mudah

2. Sistem jaringan (transportasi). Hal yang dapat dilakukan, misalnya meningkatkan kapasitas pelayanan prasarana yang ada, melebarkan jalan, menambah jaringan baru dan lainnya 
3. Sistem pergerakan (lalu lintas). Hal yang dapat dilakukan antara lain mengatur teknik dan manajemen lalu lintas (jangka pendek), fasilitas angkutan umum yang lebih baik (jangka pendek dan menengah), atau pembangunan jalan (jangka panjang).

Prinsip dasar angkutan umum menurut (Parikesit, 2007), yaitu:

\section{Safety and Security}

Safety dan security adalah persoalan keselamatan dan keamanan pada transportasi dimana menurut UU no 22 tahun 2009 bahwa angkutan umum massal harus mempunyai jalur trayek dan pengelolaan tersendiri untuk meningkatkan keselamatan.

\section{Efficiency}

Perubahan ke angkutan umum massal akan menekan konsumsi bahan bakar.

\section{Equity}

Asas keadilan dan pemerataan dimana semua bisa menikmati pelayanan transportasi, semua kalangan dengan harga terjangkau.

Menurut Sektor Proyek Pelayanan Konsultasi

Kebijakan Transportasi (GIZ, 2011) pengelolaan angkutan umum yang efektif dibangun di atas empat fondasi, yaitu :

1. Kebijakan yang koheren, dan strategi implementasi;

2. Struktur industri angkutan umum yang mengamini persaingan sehat atau pengendalian dengan regulasi;

3. Kerangka regulasi yang menyediakan dasar hukum untuk menyeimbangkan antara hak, kewajiban, dan insentif;

4. Kelembagaan regulasi yang memiliki kemampuan memadai dan kemandirian (otonomi) untuk melakukan perencanaan jaringan dasar, menjalankan peraturan dan mengarahkan pengembangan industri angkutan umum.

Selain empat fondasi di atas, menurut (GIZ, 2011) terdapat lima langkah penting dan hirarkis dalam penyelenggaraan sistem angkutan umum, yaitu:

1. Menentukan visi serta kebijakan transportasi perkotaan yang koheren, dan menyusun garis-garis besar strategi implementasi;

2. Menginisiasi proses perencanaan yang efektif;

3. Menentukan komposisi dari struktur industri angkutan umum;

4. Mengembangkan kerangka regulasi yang tepat;

5. Membentuk lembaga perencanaan dan regulator yang efektif;

\section{METODOLOGI PENELITIAN}

\section{Bagan Alir}

Bagan alir penelitian ini dapat dijelaskan pada Gambar 1. Berikut:

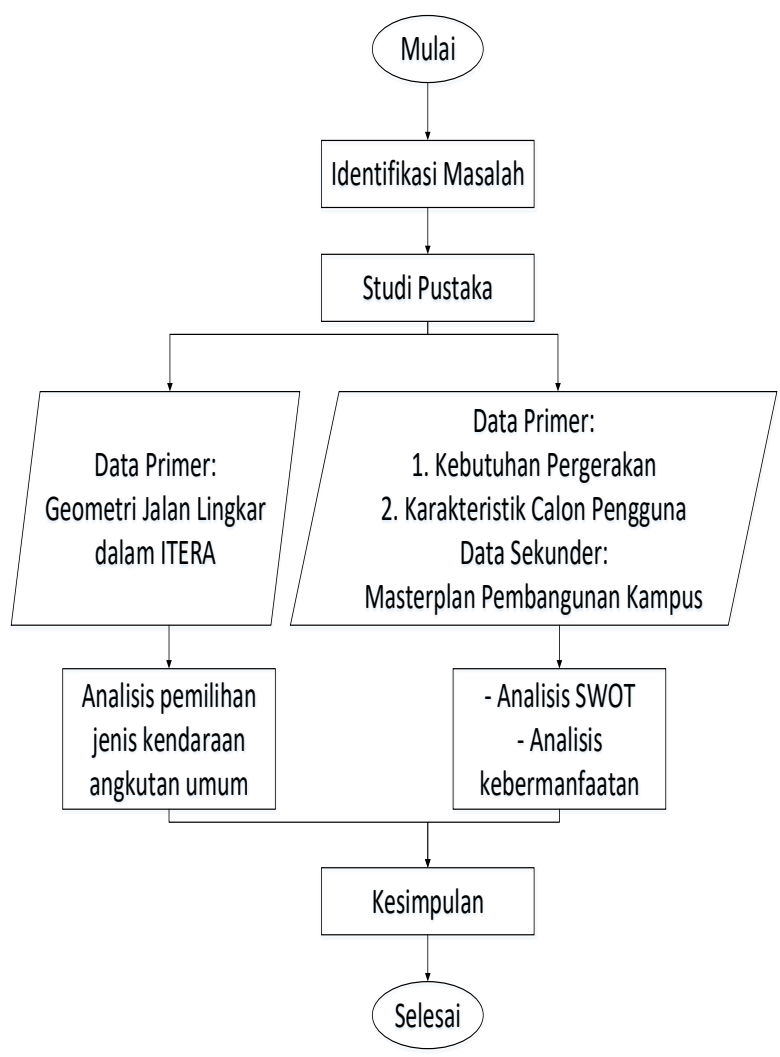

Gambar 1. Bagan alir penelitian

Bagan alir penelitian terdapat pada Gambar 1 diatas. Penelitian diawali dengan mengidentifikasikan permasalahan yaitu adanya kebutuhan angkutan umum untuk melayani pergerakan sivitas akademika di lingkungan kampus ITERA.

Pada penelitian ini, data yang dibutuhkan diambil dengan menggunakan dua metode survei yaitu survei primer dan pengumpulan data sekunder. Survei primer dilakukan dengan cara observasi langsung di wilayah 
studi dan wawancara kuisioner untuk mendapatkan informasi mengenai karakteristik, persepsi dan harapan calon pengguna layanan angkutan umum internal kampus. Data karakteristik responden diperoleh dengan cara pembagian kuisioner kepada calon pengguna angkutan, lalu dianalisis secara statistik-deskriptif.

Menurut Munawar (2004), survei geometri perlu dilakukan dalam perencanaan angkutan umum. Hal ini dikarenakan untuk penyesuaian jenis kendaraan yang akan digunakan sebagai moda transportasi umum tersebut. Dari penyediaannya, terdapat beberapa moda angkutan umum seperti angkutan feeder atau angkutan pengumpan yang memiliki kapasitas penumpang dalam satu kali pengangkutan yaitu 8-12 orang, angkutan bus kecil/sedang, hingga bus besar yang bersifat massal dan melayani pergerakan wilayah perkotaan atau dikenal dengan Bus Rapid Transit (BRT).

Berdasarkan Peraturan Menteri Perhubungan No 15 Tahun 2019 tentang Penyelenggaraan Angkutan Orang dengan Kendaraan Bermotor Umum dalam Trayek, berikut merupakan ukuran berbagai jenis moda kendaraan angkutan umum:

Tabel 1. Ukuran jenis angkutan darat

\begin{tabular}{lcc}
\hline \multirow{2}{*}{ Jenis Angkutan } & \multicolumn{2}{c}{ Dimensi } \\
\cline { 2 - 3 } & Lebar (m) & Berat (Kg) \\
Mobil Penumpang & $<2,1$ & $<3500$ \\
Mobil Bus Kecil & Maks 2,1 & $3500-5000$ \\
Mobil Bus Sedang & Maks2,1 & $5000-8000$ \\
Mobil Bus Besar & Maks 2,5 & $8000-16000$ \\
\hline
\end{tabular}

Pengambilan data geometri jalan dilakukan di ruas jalan dan persimpangan yang terdapat pada jaringan jalan wilayah dalam kampus ITERA. Data ini meliputi lebar jalan, kelandaian, dan lebar jalur pedestrian. Dari data tersebut, dapat ditentukan jenis kendaraan yang paling sesuai untuk melayani jaringan rute kampus ITERA. Menurut Eboli (2007), salah satu indikator penilaian kualitas pelayanan angkutan umum, ditinjau dari faktor kenyamanan adalah jumlah daya angkut. Adapun aspek tersebut tergantung kepada kebutuhan dan jenis pergerakan internal yang dilakukan oleh sivitas akademika. Populasi pada penelitian ini yaitu seluruh sivitas akademika ITERA yaitu dosen, tenaga kependidikan, dan mahasiswa. Selain itu dilakukan analisis prasarana jalan eksisting yang terdapat di lingkungan kampus. Setelah didapatkan jenis permintaan pergerakan dan kondisi jalan eksisting, maka dapat dilakukan kajian normatif terhadap peraturan perundangan yang berlaku mengenai analisis perbandingan jenis angkutan darat yang dapat digunakan untuk melayani pergerakan internal kampus.

\section{HASIL DAN PEMBAHASAN}

Survei jenis kebutuhan dan bentuk pergerakan dilakukan kepada sivitas akademika dan non sivitas akademika. Adapun non sivitas akademik adalah tamu maupun masyarakat umum yang menggunakan fasilitas dari kampus. Dari hasil survei yang dilakukan, berikut merupakan tabel kebutuhan dan bentuk pergerakan sivitas akademika ITERA:

Tabel 2. Kebutuhan dan bentuk pergerakan sivitas akademika ITERA

\begin{tabular}{|c|c|c|}
\hline Objek & $\begin{array}{l}\text { Kebutuhan } \\
\text { Pergerakan }\end{array}$ & $\begin{array}{c}\text { Bentuk } \\
\text { Pergerakan }\end{array}$ \\
\hline \multirow{4}{*}{$\begin{array}{l}\text { Sivitas } \\
\text { Akademika } \\
\text { ITERA }\end{array}$} & $\begin{array}{l}\text { Akademik (prodi } \\
\text { prodi) \& non akademik }\end{array}$ & \multirow{4}{*}{$\begin{array}{l}\text { - Masuk dan } \\
\text { keluar } \\
\text { kampus } \\
\text { - Mobilisasi } \\
\text { antar } \\
\text { gedung }\end{array}$} \\
\hline & Urusan administrasi & \\
\hline & Kemahasiswaan & \\
\hline & $\begin{array}{l}\text { Kegiatan perkuliahan } \\
\text { dan } \\
\text { organisasi }\end{array}$ & \\
\hline \multirow{11}{*}{$\begin{array}{l}\text { Non-Sivitas } \\
\text { Akademika } \\
\text { ITERA }\end{array}$} & Tamu rektorat & - Masuk dan \\
\hline & & keluar \\
\hline & & $\begin{array}{l}\text { Kampus } \\
\text { menuju }\end{array}$ \\
\hline & & Gedung \\
\hline & & Rektorat \\
\hline & fakultas/jur & $\begin{array}{l}\text { - Masuk dan } \\
\text { keluar }\end{array}$ \\
\hline & $\begin{array}{l}\text { usan/ } \\
\text { prodi }\end{array}$ & kampus \\
\hline & Ruang akses public & \multirow{2}{*}{$\begin{array}{l}\text { Masuk dan } \\
\text { keluar } \\
\text { kampus } \\
\text { menuju } \\
\end{array}$} \\
\hline & Melintas & \\
\hline & Ruang akses public & \multirow{2}{*}{$\begin{array}{l}\text { - Melintas di } \\
\text { kawasan } \\
\text { kampus } \\
\end{array}$} \\
\hline & Melintas & \\
\hline
\end{tabular}

Sumber: Hasil Analisis, 2020 


\section{Data Karakteristik Responden Sivitas Akademika ITERA}

Dari jenis moda yang digunakan dalam menuju dan meninggalkan kampus ITERA, berikut merupakan penjabaran data tersebut pada Gambar 2.

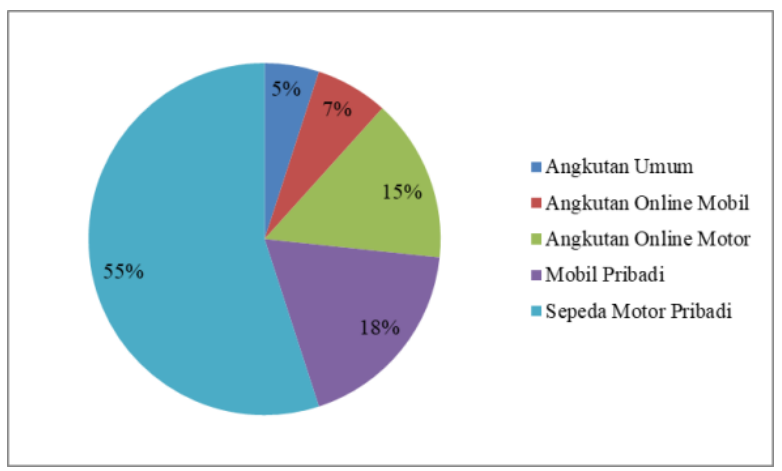

Gambar 2. Jenis moda yang digunakan

Dari Gambar diatas dapat diketahui bahwa sebesar $27 \%$ dari sivitas akademika ITERA, tidak memiliki kendaraan pribadi. Adapun untuk pergerakan internal kampus, hal ini menjadi permasalahan dikarenakan tidak tersedianya moda yang mengakomodir kebutuhan perjalanan internal seperti yang tertera pada Tabel 2 yang telah dijelaskan sebelumnya.

Jenis moda yang digunakan untuk berpindah akan berkaitan erat dengan besarnya biaya perjalanan, adapun hasil survei mengenai hal tersebut dapat dijelaskan pada Gambar 3 berikut:

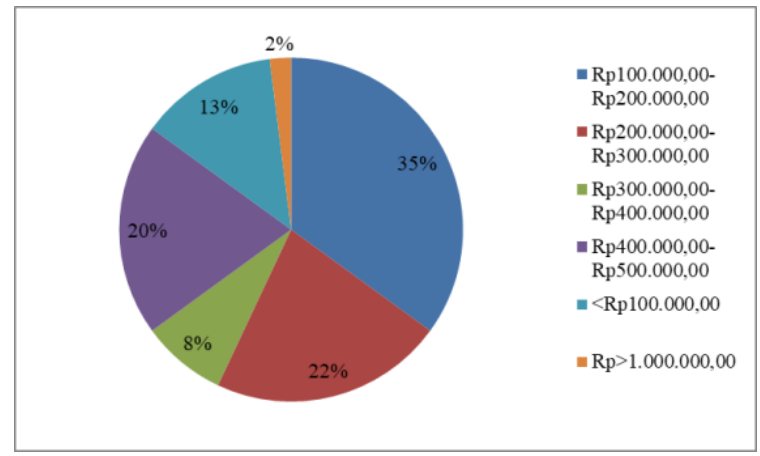

Gambar 3. Biaya transportasi per bulan

Berdasarkan Gambar 3 diatas, dapat diketahui bahwa sebesar $35 \%$ atau responden mayoritas menghabiskan biaya untuk transportasi sebesar Rp100.000,00 hingga Rp200.000,00 per bulan.
Dari kebutuhan dan bentuk pergerakan sivitas akademika ITERA yang tertera pada Tabel 2, adapun untuk waktu perpindahan antar gedung yang paling banyak dilalui oleh sivitas akademika ITERA adalah sebagai berikut:

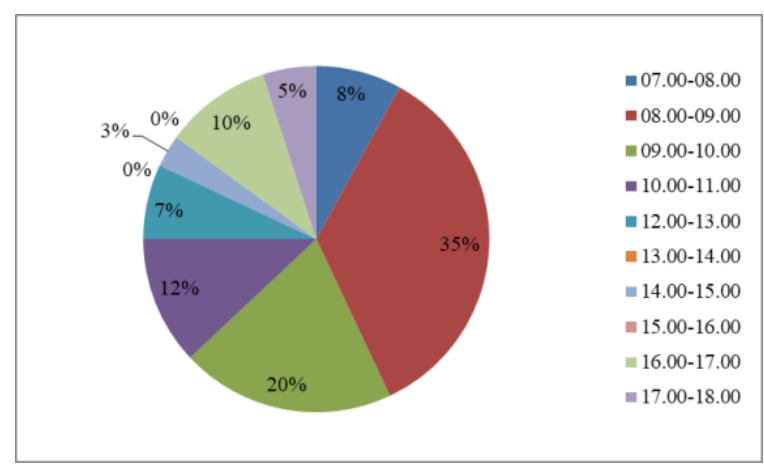

Gambar 4. Jadwal perpindahan antar gedung

Selanjutnya yaitu, dari kelompok pengguna choice atau yang memiliki piihan antara menggunakan kendaraan pribadi maupun angkutan umum, maka dilakukan survei kembali mengenai kesediaan untuk berpindah menggunakan angkutan umum yang melayani wilayah kampus ITERA, apabila telah tersedianya fasilitas tersebut. Berikut merupakan hasil survei yang tergambar pada Gambar 5. berikut:

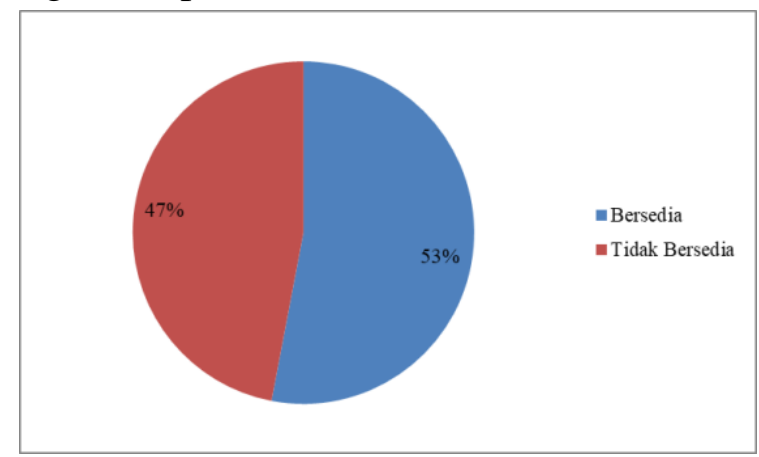

Gambar 5. Kesediaan berganti moda

Dari Gambar 5 diatas dapat diketahui bahwa sebesar 53\% dari responden kelompok Choice bersedia untuk berpindah menggunakan angktan umum layanan dalam kampus dalam melakukan pergerakan internal. Besarnya persentase hal ini menjadi kriteria utama dalam keberhasilan perencanaan operasional pengadaan angkutan umum layanan dalam kampus selanjutnya. 


\section{Data Lebar Ruas Jalan Internal Kampus ITERA}

Untuk data lebar ruas jalan lingkar dalam kampus ITERA dapat terlihat pada Tabel berikut:

Tabel 3. Data lebar ruas jalan lingkar dalam ITERA

\begin{tabular}{lccc}
\hline \multicolumn{1}{c}{ Ruas Jalan } & $\begin{array}{c}\text { Lebar } \\
\text { Lajur (m) }\end{array}$ & $\begin{array}{c}\text { Jumla } \\
\mathbf{h} \\
\text { Lajur }\end{array}$ & $\begin{array}{c}\text { Jumla } \\
\text { h Arah }\end{array}$ \\
\hline Gerbang Utama & 4,5 & 2 & 2 \\
Gedung & & & \\
Rektorat & 3,5 & 2 & 2 \\
Jalan Asrama & 3 & 2 & 2 \\
Jalan Gedung E & 5 & 2 & 2 \\
Jalan GKU 1 & 3,5 & 2 & 2 \\
Jalan Gedung F & 3 & 2 & 2 \\
\hline Sumber: Hasil Analisis, 2020 & &
\end{tabular}

Dari kondisi jalan eksisting lingkar dalam kampus yang terdapat pada Tabel 3 di atas, dapat disimpulkan bahwa jalan lingkar dalam ITERA secara keseluruhan memiliki lebar lajur masing-masing 3m, jumlah lajur masingmasing ruas jalan adalah 2 dan 2 arah, sehingga dari analisis kesesuaian jenis kendaraan angkutan umum darat pada Tabel 1, yang dapat digunakan untuk melayani pergerakan internal kampus, yaitu kendaraan mobil penumpang, bus kecil/sedang hingga bus besar.

\section{Analisis SWOT}

Untuk mengetahui aspek-aspek apa saja yang menjadi dasar penguatan bahwa dibutuhkannya suatu layanan angkutan umum di internal kampus ITERA, berikut pada Tabel 3. merupakan analisis SWOT mengenai hal tersebut.

Tabel 4. Analisis SWOT

Belum tersedianya angkutan umum layanan pergerakan internal kampus ITERA

ITERA merupakan kampus dengan slogan Smart, Friendly, and

Strength

Forrest Campus

ITERA merupakan institut teknologi negeri yang terus melakukan inovasi dalam ilmu pengetahuan dan teknologi sesuai dengan kebutuhan di pulau Sumatera
ITERA memiliki Teknologi sistem informasi yang baik oleh UPT TIK, salah satunya aplikasi POCKET bagi seluruh sivitas akademika Lokasi kampus strategis yaitu berjarak $\pm 1 \mathrm{~km}$ dari Gerbang Tol Kotabaru, yang merupakan salah satu akses dari dan menuju Jalan Tol Trans Sumatera. Jika dilakukan pengembangan pelayanan angkutan umum wilayah eksternal ITERA, akan menguntungkan

\begin{tabular}{cl} 
Weakness & $\begin{array}{l}\text { Tidak terdapat prasarana seperti } \\
\text { bengkel, pool, di ITERA }\end{array}$ \\
\hline \multirow{3}{*}{ Opportunity } & $\begin{array}{l}\text { Kajian penyediaan angkutan } \\
\text { internal kampus dapat dilakukan } \\
\text { oleh peneliti dari sivitas akademika } \\
\text { ITERA }\end{array}$ \\
\hline \multirow{2}{*}{ Threat } & $\begin{array}{l}\text { Sebesar 47\% kelompok pengguna } \\
\text { Choice masih ingin menggunakan } \\
\text { kendaraan pribadi pada pergerakan } \\
\text { internal kampus }\end{array}$ \\
\hline
\end{tabular}
Sumber: Hasil Analisis, 2020

Adapun analisis SWOT yang terdapat pada Tabel 3 diatas yaitu bertujuan untuk mengidentifikasi hal-hal apa saja yang menjadi dasar dibutuhkannya angkutan umum layanan pergerakan internal kampus, tantangan serta dilengkapi dengan beberapa strategi penyelesaian masalah. Dengan adanya kekuatan dan kesempatan, maka dianalisis strategi jangka panjang apa yang dapat dilakukan. Begitupula dengan teridentifikasinya kelemahan dan tantangan pada Analisis SWOT, dapat dilakukan strategi untuk mengatasi hal tersebut. Berikut merupakan rekapitulasi strategi penyelesaian masalah pada masing-masing aspek adalah pada Tabel 4.

Tabel 5. Strategi penyelesaian masalah

\begin{tabular}{|c|c|}
\hline$S-O$ & $\begin{array}{l}\text { Setelah diketahui justifikasi mengenai } \\
\text { kebutuhan angkutan umum dalam } \\
\text { kampus, dapat dilakukan kajian } \\
\text { penyediaan operasional angkutan } \\
\text { dalam kampus oleh peneliti dari } \\
\text { sivitas akademika ITERA }\end{array}$ \\
\hline$W-O$ & $\begin{array}{l}\text { Melakukan kerjasama di bidang } \\
\text { penelitian atau MoU dengan pihak } \\
\text { pengelola angkutan umum, seperti } \\
\text { Damri, dalam hal penggunaan } \\
\text { prasarana seperti bengkel, pool, dll }\end{array}$ \\
\hline
\end{tabular}




\begin{tabular}{cl}
\hline & $\begin{array}{l}\text { Sistem informasi pada pelayanan } \\
\text { angkutan umum dalam kampus dapat } \\
\text { bersifat real time bagi sivitas } \\
\text { akademika, yaitu melalui aplikasi } \\
\text { POCKET }\end{array}$ \\
\hline Meyakinkan kelompok pengguna \\
choice untuk menggunakan angkutan \\
umum dalam kampus dengan \\
membangun sistem transportasi yang \\
berkelanjutan
\end{tabular}

\section{Analisis Sosial dan Ekonomi}

Dari kondisi eksisting dapat diketahui bahwa pergerakan internal kampus hanya dapat diakomodir oleh angkutan umum yang bersifat online, berjalan kaki, dan menggunakan kendaraan pribadi. Hal ini jika diproyeksikan ke jangka panjang, tentunya akan memiliki dampak negatif, antara lain: biaya transportasi yang tinggi; serta produktifitas dalam kegiatan akademik dan non akademik di kampus ITERA. Dari hasil analisis yang dilakukan, adapun tarif per $4 \mathrm{~km}$ pertama angkutan sepeda motor online saat ini yaitu sebesar Rp10.000,00 setiap satu kali perjalanan. Adapun jika dibandingkan dengan penggunaan angkutan umum dalam kampus, hal ini dapat berdampak pada menurunnya biaya transportasi sivitas akademika yang dikeluarkan setiap bulannya.

Penggunaan angkutan umum tentu akan mengurangi jumlah kendaraan yang melintas di suatu wilayah, hal ini tentu akan berdampak pada tingkat polusi udara maupun suara/kebisingan yang dihasilkan akan berkurang secara signifikan. Dengan situasi yang minim akan polusi tentu akan tercipta suasana lingkungan yang kondusif untuk kegiatan belajar dan mengajar.

\section{KESIMPULAN}

Dari hasil penelitian dapat diketahui bahwa saat ini Kampus ITERA telah membutuhkan perencanaan bus kampus untuk mengakomodir pergerakan internal. Hal ini didasarkan oleh hasil analisis hasil survei karakteristik pergerakan sivitas akademika ITERA, dapat diketahui frekuensi perpindahan antar gedung yang tinggi dengan waktu perpindahan tertinggi terjadi pada pagi hari. Adapun sebanyak 27\% sivitas akademika ITERA tidak memiliki kendaraan pribadi, sehingga pergerakan diakomodir dengan berjalan kaki dan menggunakan angkutan online.

Dari analisis SWOT, dapat diketahui bahwa adanya bus kampus akan meningkatkan konektivitas pergerakan yang akan mendukung sistem transportasi berkelanjutan di Provinsi Lampung. Dengan kondisi geometri jalan lingkar dalam kampus ITERA, dari lebar dan topografi jalan memenuhi kriteria untuk pelayanan oleh jenis kendaraan angkutan pengumpan ataupun bus kecil hingga sedang. Dari kajian kebutuhan bus kampus ini dapat dilakukan penelitian selanjutnya yaitu berupa analisis kajian perencanaan angkutan umum di wilayah internal kampus ITERA, yang melingkupi aspek operasional seperti headway, perencanaan halte, penjadwalan, perancangan jaringan rute bus kampus.

\section{UCAPAN TERIMA KASIH}

Terima kasih kepada Lembaga Penelitian, Pengabdian Masyarakat dan Lembaga Penjaminan Mutu Institut Teknologi Sumatera yang telah membiayai penelitian ini.

\section{REFERENSI}

Adisasmita, S.A., 2011. Jaringan Transportasi: Teori dan Analisis. Graha Ilmu, Yogyakarta.

Balsas, C.J.L., 2003. Sustainable Transportation Planning on College Campuses, Transport Policy. 35-49.

Basuki, I, dkk., 2020. Studi Kelayakan Penyelenggaraan Bus Kampus Atma Jaya Babarsari Yogyakarta. Jurnal Transportasi. 20(1): 57-66.

Diayudha, L., 2011. Persepsi Mahasiswa Terhadap Efektivitas Penggunaan Bus Kampus Universitas Bunda Mulia. Business \& Management Journal Bunda Mulia, 7. 
Eboli, L dkk., 2007. Service Quality Attributes Affecting Customer Satisfaction for Bus Transit. Journal of Public Transportation. 10(3).

GTZ, 2003. Sustainable Urban Transport Sourceboo for Policy-makers in Developing Cities, Germany: TZ Verlagsgessellchaft $\mathrm{mbH}$.

Kementerian Pekerjaan Umum dan Perumahan Rakyat Badan Pengembangan Sumber Daya Manusia, 2017. DasarDasar Perencanaan Geometrik Ruas Jalan, Pusat Pendidikan dan Pelatihan Jalan, Perumahan, Permukiman dan Pengembangan Infrastruktur Wilayah, Bandung.

Khisty, C.J., 2003. Dasar-dasar Rekayasa Transportasi, Jilid 1 edisi ketiga. Erlangga, Jakarta.

Masterplan ITERA Rencana Pengembangan Tahun 2017-2027.

Meakin, R., 2011. Regulasi dan Perencanaan Bus. GIZ, Eschborn.

Munawar, A., 2004. Analisis Sistem Jaringan Transportasi di Kampus UGM. Media Teknik. 3(26).

Parikesit, D. 2007. Sistem Transportasi Indonesia: Menggagas Tatanan Baru Transportasi bagi Indonesia yang Maju dan Sejahtera. Seminar Nasional KAGAMA [tidak dipublikasikan], Universitas Gadjah Mada, Yogyakarta.

Rugayah, H., dkk., 2013. Assessment of Campus Bus Service Efficacy: An Application Towards Green Environment, Procedia - Social and Behavioral Sciences 105: 294-303.

Sulviawan, P.A., dkk., 2014. Pemodelan Rute Bus Kampus UNDIP Tembalang dengan Aplikasi Sistem Informasi Geografis (SIG). Jurnal Teknik PWK. 3(4):841-866.

Peraturan Menteri Perhubungan No 15 Tahun 2019 tentang Penyelenggaraan Angkutan Orang dengan Kendaraan Bermotor Umum dalam Trayek.
Undang-Undang Nomor 22 Tahun 2009 tentang Lalu Lintas Angkutan Jalan. 